ORIGINAL PAPER

\title{
Evaluation of THE ROLE of EPSTEIN-BARR Virus in CASES OF NODAL OR EXTRANODAL T- AND NK-CELL LYMPHOMA USING EBER IN SITU HYBRIDIZATION
}

\author{
Serap Karaarslan ${ }^{1}$, Mine Hekimgil ${ }^{2}$, Saliha Soydan ${ }^{2}$, Yeşim Ertan ${ }^{2}$, Başak Doğanavģargil ${ }^{2}$
}

${ }^{1}$ Department of Pathology, Sifa University Faculty of Medicine, Izmir, Turkey

${ }^{2}$ Department of Pathology, Ege University Faculty of Medicine, Izmir, Turkey

\begin{abstract}
Various racial and geographic differences have been observed in studies questioning the role of Epstein-Barr virus (EBV) infection in the etiology of T- and NK-cell lymphomas. The aim of this study was to evaluate the relationship of EBV with nodal or extranodal (skin excluded) T- and NK-cell lymphoma subtypes encountered in our geographic area. Sixty-two cases of peripheral T-cell lymphoma were included in the study. EBV-encoded early RNA (EBER) was detected by in situ hybridization. The distributions of T- and NK-cell lymphoma subtypes were as follows: 32 peripheral T-cell lymphomas, unspecified (PTCL, NOS), 13 anaplastic large-cell lymphomas (ALCL), 8 angioimmunoblastic T-cell lymphomas (AIT$\mathrm{CL}$ ), 4 extranodal NK/T-cell lymphomas, nasal type (NKTCL), 3 enteropathy-type T-cell lymphomas (ETTCL), 1 hepatosplenic T-cell lymphoma (HSTCL), and 1 subcutaneous panniculitis-like T-cell lymphoma (SPTCL). Using a cut-off value of $>25 \%$ of EBER-positive neoplastic lymphoid cells, EBV was positive in $22.6 \%$ of all cases. According to subtype, the neoplastic cells of $31.3 \%$ of PTCL, NOS and $100 \%$ of extranodal NKTCL, nasal type were EBER positive, whereas some cases of ALCL, AITCL, and ETTCL presented EBER-positive non-neoplastic cells, and all cells of HSTCL and SPTCL were EBV negative. Extranodal NKTCL, nasal type, presented the strongest association with EBV, followed by PTCL, NOS.
\end{abstract}

Key words: lymphoma, T-cell, extranodal NK-T-cell, EBV, EBER, in situ hybridization.

\section{Introduction}

Since "natural killer" (NK) cells are closely related to T-cells, their neoplasms were integrated into "mature T- and NK-cell neoplasms" in the WHO classification [1]. T- and NK-cell lymphomas, which comprise $12-15 \%$ of all non-Hodgkin's lymphomas (NHL), are a group of NHL with aggressive clinical behaviour [2-5]. T- and NK-cell neoplasms are more common in Asia [5, 6]; indeed, the incidences of nasal and nasal type NK/T-cell lymphomas and aggressive NK/T-cell lymphomas are highest in Asians [7, 8].
While Epstein-Barr virus (EBV) has been mostly linked to B-cell neoplasms, some EBV-associated T- and NK-cell lymphomas have been reported, especially those with a cytotoxic phenotype and aggressive behaviour [9]. Various racial and geographic differences have been reported in studies of the role of EBV infection in the etiology of T- and NK-cell lymphomas. Most reported cases are from Asia and Latin America, consistent with the higher incidence in these regions. It has been proposed that EBV-encoded RNA promotes the proliferation and transformation of T-cells [10, 11]. An association between EBV and 
nasal NK/T-cell lymphomas has been demonstrated [5, 11-17]. Recent studies on various other subtypes of T- and NK-cell lymphomas, such as peripheral T-cell lymphoma, unspecified (PTCL, NOS) $[18$, 19], angioimmunoblastic T-cell lymphoma (AITCL) [20], enteropathy type T-cell lymphoma (ETTCL) $[21,22]$, and hepatosplenic T-cell lymphoma (HSTCL) [23], have also reported a possible role for EBV as an aetiopathogenetic factor. In most T- and NK-cell neoplasms, EBV latency type II has been reported expressing the latency proteins LMP-1, 2a, 2b, EBNA1 and EBERs [24].

The aim of this study was to evaluate the relationship of EBV with nodal or extranodal (excluding the skin) T- and NK-cell lymphoma subtypes encountered in our geographic area. We evaluated the incidence of EBV latency in our archival material using chromogenic in situ hybridization to demonstrate EBV-encoded early RNA (EBER), which is the most reliable method reported to date [25].

\section{Material and methods}

Tissue samples from cases diagnosed as nodal or extranodal T- and NK-cell lymphomas during a seven-year period between 1997 and 2004 were retrieved from the archives. Cases with cutaneous or leukaemic presentation were excluded from the study. Sixty-two cases with available paraffin-embedded tissue were studied. Tissue sections, $4 \mu \mathrm{m}$ thick, were prepared from formalin-fixed, paraffin-embedded tissues and were placed on electrostatic-charged slides (X-tra, Surgipath Medical Industries, Richmond, IL, USA). EBER was detected by in situ hybridization using an automated system (Benchmark XT, Ventana Medical Systems, Tucson, USA), an EBER probe (INFORM EBER Probe, Ventana Medical Systems, Tucson, USA) and a readyto-use in situ hybridization kit (ISH iVIEW Blue Detection Kit, Ventana Medical Systems, Tucson, USA). Samples from five cases of Hodgkin's lymphoma known to be positive for EBV LMP-1 by immunohistochemical methods and a lymph node from a case of infectious mononucleosis were included as positive controls. A positive reaction was identified by the appearance of a greyish-blue precipitate detected by examination under a light microscope. This evaluation was performed by two pathologists (SK, MH) and scored as below according to the percentage of positive cells (Fig. 1).
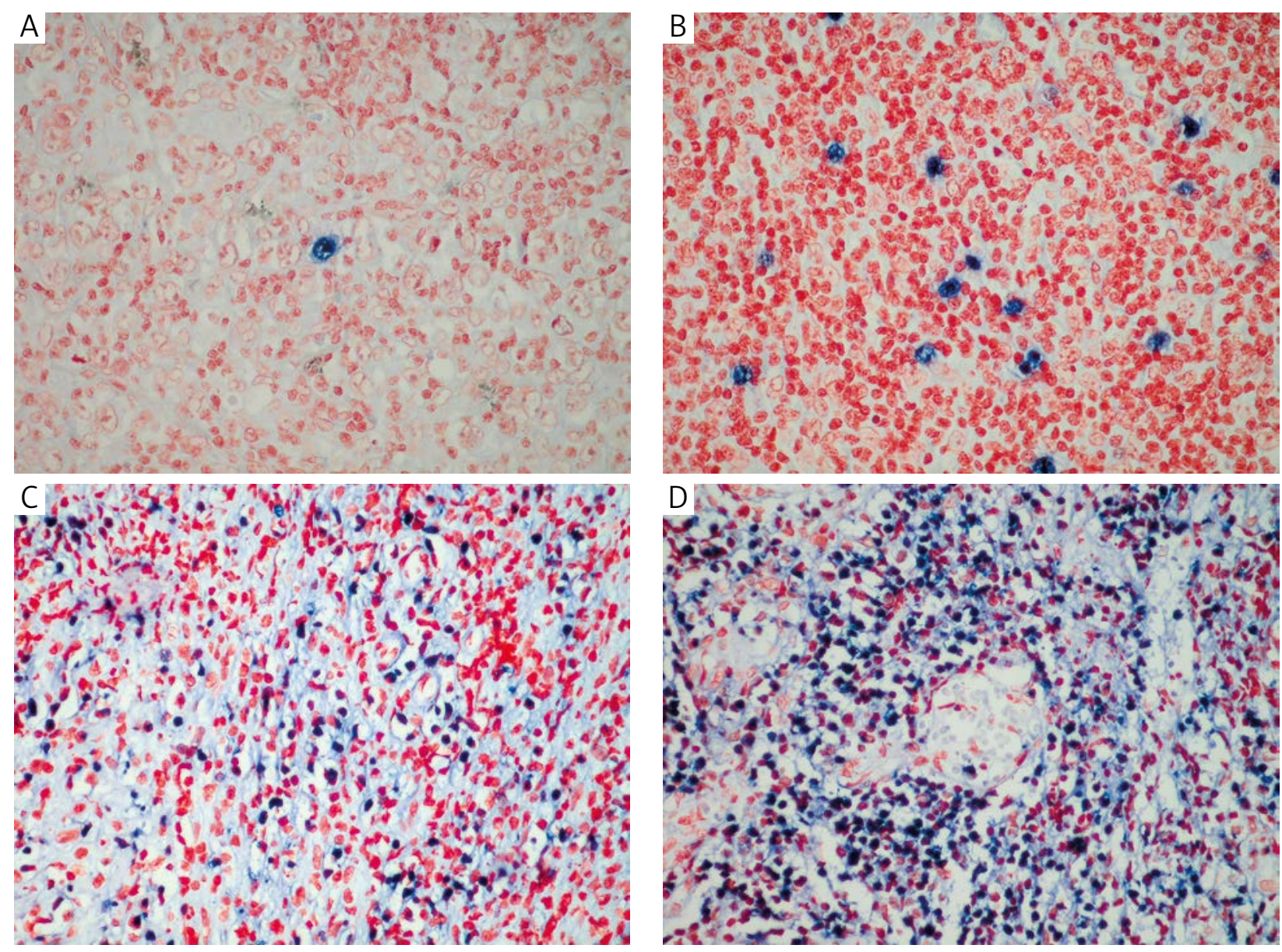

Fig. 1. Grading of EBER reaction (in situ hybridization, NBT). A) Grade 1+, magnification 40×. B) Grade 2+, magnification $40 \times$. C) Grade 3+, magnification $20 \times$. D) Grade 4+, magnification $20 \times$ 
Criteria used in grading the EBER staining pattern: 0 : No reaction in any cell.

$1+$ : Scarce EBER-positive cells $(<5 \%)$, suggestive of isolated reactive or activated lymphoid cells and/ or immunoblasts.

2+: Few EBER-positive cells (5-25\%), discordance with the morphology of neoplastic cells, consistent with reactive or activated lymphoid cells and/or immunoblasts.

3+: Some neoplastic cells (26-75\%) EBER positive. $4+$ : All neoplastic cells $(>75 \%)$ EBER positive.

Only grade $3+$ and $4+$ cases, with a cut-off value $>25 \%$ EBER-positive neoplastic cells, were accepted as being EBV positive.

\section{Statistical analysis}

Statistical analyses were conducted using the SPSS software (version 14.0). Pearson's $\chi^{2}$ and Fisher's exact tests were used to compare the associations between the histological subtypes and EBER positivity. A p value $<0.05$ was accepted to indicate statistical significance.

\section{Results}

Of the 62 cases studied, the subtypes, in order of decreasing frequency, were as follows: 32 PTCL, NOS (51.6\%), 13 anaplastic large-cell lymphomas (ALCL) (21.0\%), 8 AITCL (12.9\%), 4 extranodal NK/TCL, nasal type (6.5\%), 3 ETTCL (4.8\%), 1 HSTCL (1.6\%), and 1 subcutaneous panniculitis-like T-cell lymphoma (SPTCL) (1.6\%). The age and sex distributions of the cases are summarised in Table I.

Of the subtypes known to present with nodal involvement ( $\mathrm{n}=53$ ), most were diagnosed by analysing lymph node biopsies (74.0\%), and some cases using the skin (38.4\%). All subtypes known to present in extranodal sites $(n=9)$ were diagnosed in their spe- cific locations. A total of 39 lymph nodes were examined in 22 cases of PTCL, NOS, 9 cases of ALCL, and 8 cases of AITCL. The remaining 23 samples comprised cases that involved various extranodal locations. These included skin $(\mathrm{n}=3)$, bone marrow $(\mathrm{n}=2)$, spleen $(n=1)$, spleen and liver $(n=1)$, thorax $(n=1)$, tonsil and root of tongue $(\mathrm{n}=1)$, and nasopharynx $(\mathrm{n}=1)$ in PTCL, NOS. Extranodal ALCL cases were sampled from the thymus and $\operatorname{lung}(\mathrm{n}=1), \operatorname{skin}(\mathrm{n}=2)$, and perirectal area $(n=1)$. Extranodal NK/T-cell lymphomas presented with involvement of the nasal cavity ( $\mathrm{n}=2)$, maxilla and orbits $(\mathrm{n}=1)$, and nasopharynx $(n=1)$. All cases of ETTCL $(n=3)$ were diagnosed from biopsies and/or small intestinal material obtained during surgery. As expected, the only case of HSTCL presented with involvement of the spleen, liver, and lymph nodes, while subcutaneous soft tissue was involved in the case diagnosed as SPTCL.

Neoplastic cells in 14 cases (22.6\%) were determined to be EBER positive. As a result, of the 14 EBV-positive nodal or extranodal (noncutaneous) T- and NK-cell lymphomas, only PTCL, NOS and extranodal NK/T-cell lymphoma, nasal type were positive, which constituted $71.4 \%$ and $28.6 \%$, respectively, of the positive cases. The EBER staining pattern intensity of these subtypes is presented in Table II.

Peripheral T-cell lymphomas, NOS was found to be EBER positive in 10 of 32 cases, and the staining pattern was diffuse in most samples, although an intense staining pattern was observed in 2 cases graded as $4+$. All 13 cases of ALCL, characterised by large, pleomorphic, often horseshoe-shaped nuclei, were EBV negative, but 2 cases exhibited grade 1 and 2 positivity that was confined to rare, small lymphoid cells, which may be bystander B-cells (Fig. 2).

AITCL is characterised by a polymorphous lymphoid infiltrate, florid vascular proliferation, and follicular dendritic cell proliferation. Five of 8 cases of AITCL examined in this study were graded as $1+$

Table I. Age and sex distribution of various histopathological subtypes

\begin{tabular}{|c|c|c|c|}
\hline HistopathOLOGIC SUBTYPE & $\mathrm{N}(\%)$ & Median age (AGE RANGE) & $\begin{array}{c}\text { SEX } \\
(\mathrm{M}: \text { F RATIO })\end{array}$ \\
\hline PTCL, NOS & $32(51.6)$ & $46.6(11-75)$ & $3: 1$ \\
\hline ALCL & $13(21.0)$ & $38.7(13-79)$ & $10: 3$ \\
\hline AITCL & $8(12.9)$ & $50.6(33-80)$ & $1: 3$ \\
\hline Extranodal NK/TCL, nasal type & $4(6.5)$ & $44.7(22-66)$ & $3: 1$ \\
\hline ETTCL & $3(4.8)$ & $45.3(27-63)$ & $1: 2$ \\
\hline HSTCL & $1(1.6)$ & 19 & - \\
\hline SPTCL & $1(1.6)$ & 34 & - \\
\hline TOTAL & 62 & $44.6(11-75)$ & $2.1: 1$ \\
\hline
\end{tabular}

PTCL, NOS - peripheral T-cell lymphoma, not otherwise specified; ALCL - anaplastic large cell lymphoma; AITCL - angioimmunoblastic T-cell lymphoma; ETTCL - enteropathy type T-cell lymphoma; HSTCL - bepatosplenic T-cell lymphoma; SPTCL-subcutaneous panniculitis-like T-cell lymphoma 
Table II. Comparison of the intensity of EBER positivity on various histopathologic subtypes

\begin{tabular}{|c|c|c|c|c|c|c|}
\hline \multirow[t]{2}{*}{ Histopathologic SubTyPE } & \multicolumn{5}{|c|}{ EBER GRADE } & \multirow{2}{*}{$\begin{array}{c}\text { EBER }(+) \\
\mathrm{N}(\%)\end{array}$} \\
\hline & 0 & $1+$ & $2+$ & $3+$ & $4+$ & \\
\hline PTCL, NOS & 20 & - & 2 & 8 & 2 & $10 / 32(31.3)$ \\
\hline ALCL & 11 & 1 & 1 & - & - & $0 / 13(0)$ \\
\hline AITCL & 3 & 1 & 4 & - & - & $0 / 8(0)$ \\
\hline Extranodal NK/TCL, nasal type & - & - & - & - & 4 & $4 / 4(100)$ \\
\hline ETTCL & 2 & 1 & - & - & - & $0 / 3(0)$ \\
\hline HSTCL & 1 & - & - & - & - & $0 / 1(0)$ \\
\hline SPTCL & 1 & - & - & - & - & $0 / 1(0)$ \\
\hline TOTAL & 38 & 3 & 7 & 8 & 6 & $14 / 62(22.6)$ \\
\hline
\end{tabular}

PTCL, NOS - peripheral T-cell lymphoma, not otherwise specified; ALCL - anaplastic large cell lymphoma; AITCL - angioimmunoblastic T-cell lymphoma; ETTCL - enteropathy type T-cell lymphoma; HSTCL - hepatosplenic T-cell lymphoma; SPTCL - subcutaneous panniculitis-like T-cell lymphoma
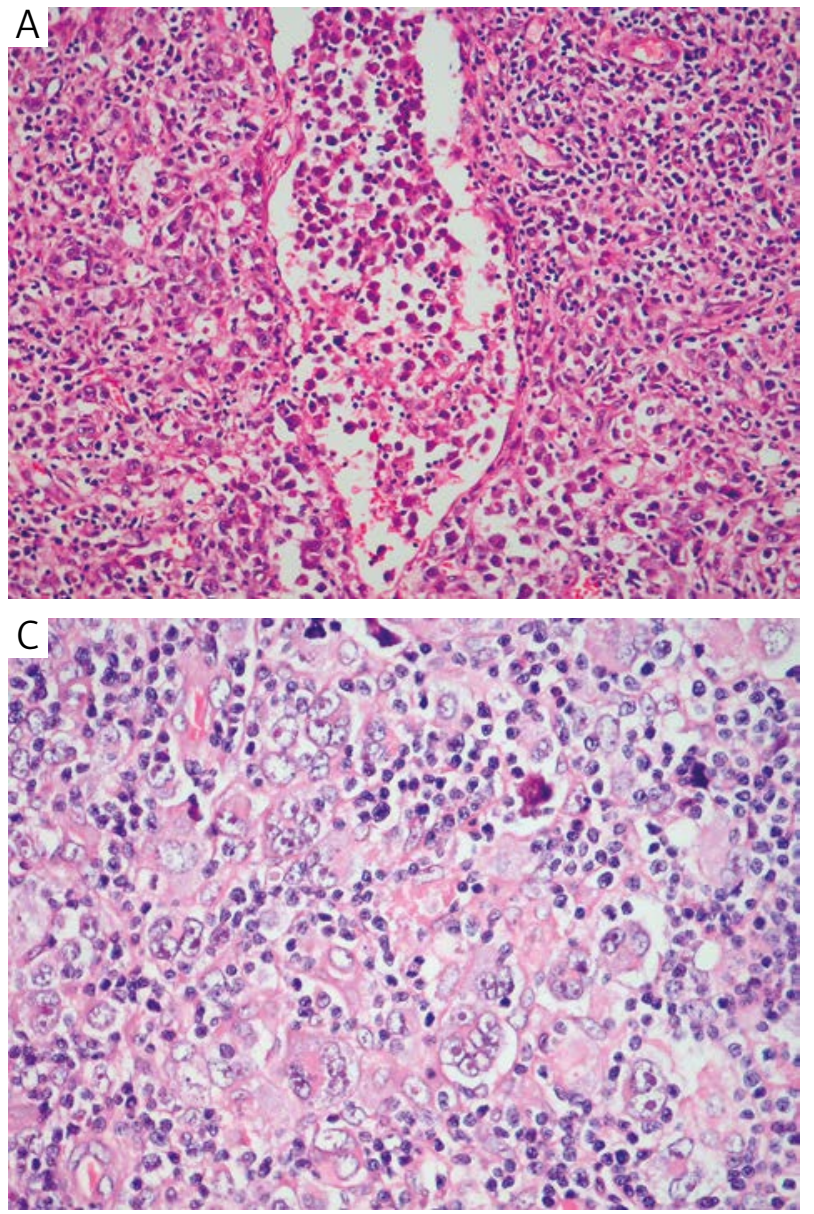

or $2+$ for EBER, on non-neoplastic large B-cells and immunoblasts, as seen in Fig. 3.

Four cases of extranodal NK/T-cell lymphoma, nasal type, presented with a typical angiocentric and angiodestructive infiltration and the associated prominent necrosis. All 4 of these cases exhibited a high level of EBER-positive staining in almost all of the neoplastic cells (Fig. 4). Extranodal NK/T-cell

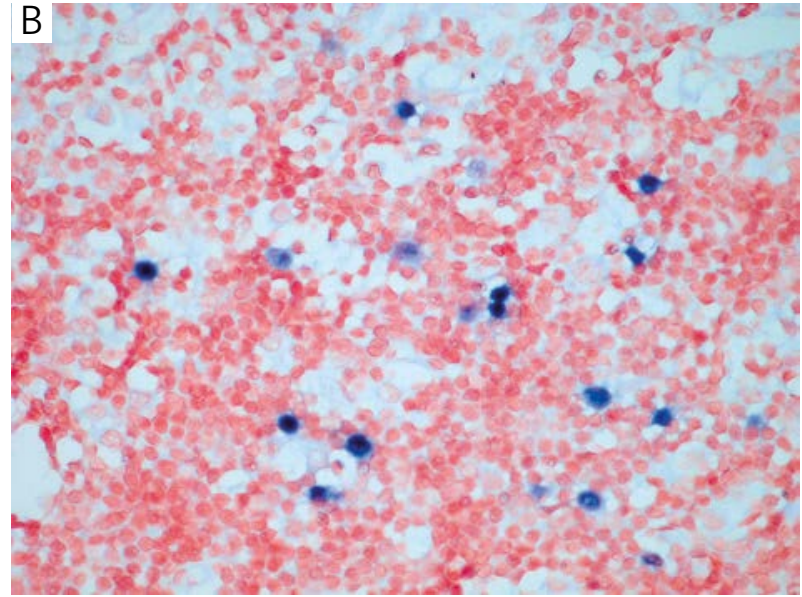

Fig. 2. Anaplastic large cell lymphoma. A) Intrasinusoidal pattern of pleomorphic tumour cells (HE, magnification 20×). B) EBER Grade 2+ (in situ hybridization, NBT, magnification 20×). C) Multiple nuclei or horseshoe-shaped nuclei of tumour cells (HE, magnification $40 \times)$

lymphoma, nasal type expressed significantly higher levels of EBER-positive staining ( $p=0.019)$. In contrast, EBER-positive staining in the other histopathological subtypes did not result in significant results.

Enteropathy-type T-cell lymphoma, an aggressive tumour of intraepithelial $\mathrm{T}$ lymphocytes common in areas with a high prevalence of coeliac disease, consisted of only 3 cases in this study. One of these cases 

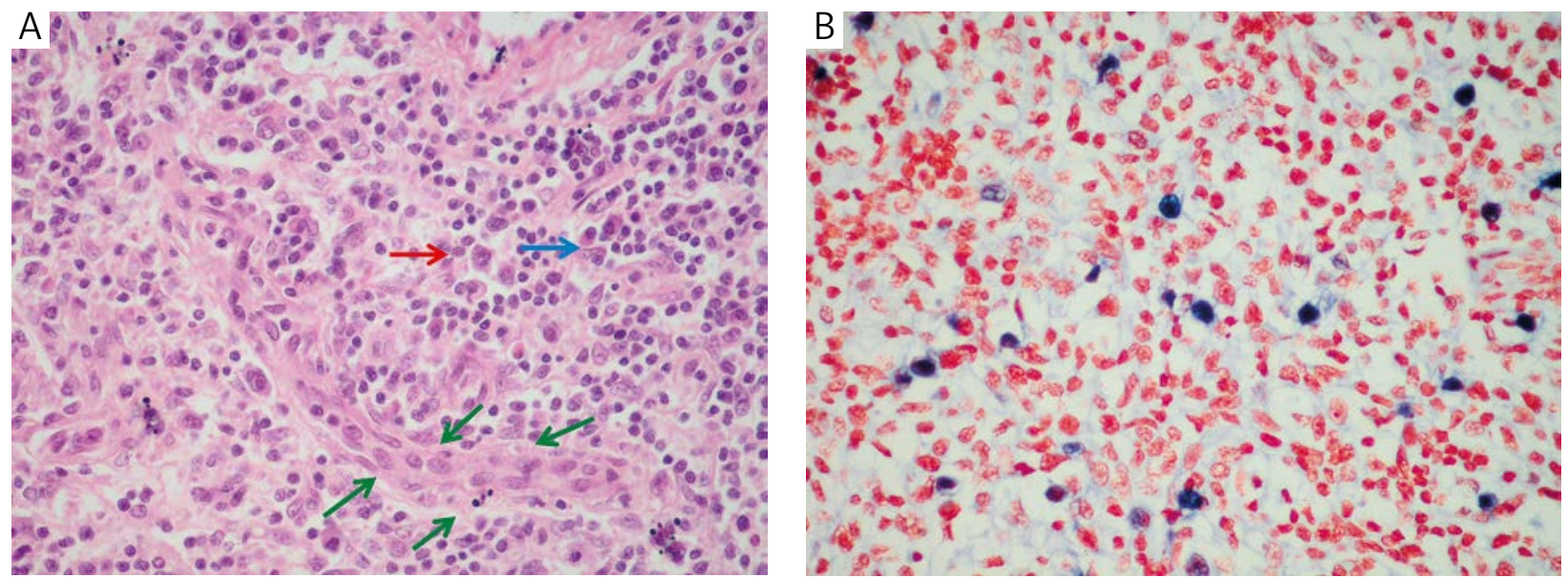

Fig. 3. Angioimmunoblastic T-cell lymphoma. A) Medium sized cells with clear cytoplasm (red arrows), reactive plasma cells (blue arrow), and immunoblasts, eosinophils, mature lymphocytes, and high endothelial proliferation (green arrows) $(\mathrm{HE}$, magnification $20 \times$ ). B) EBER Grade 2+ (in situ hybridization, NBT, magnification $20 \times)$
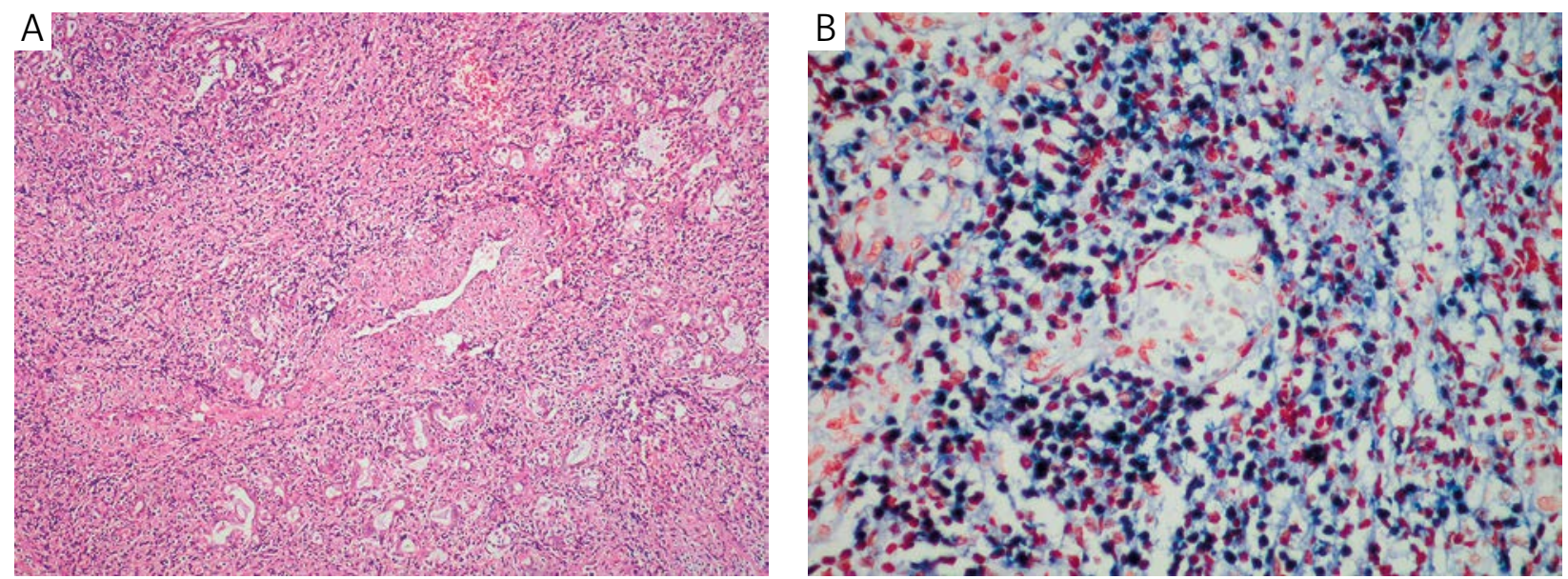

Fig. 4. Extranodal NK/T-cell lymphoma, nasal type. A) Angiocentric infiltration of medium sized cells (HE, magnification $10 \times$ ). B) EBER Grade 4+ (in situ hybridization, NBT, magnification $20 \times$ )

contained rare EBER-positive cells, which were probably reactive or exhibited an activated phenotype; notably, this finding was observed in a post-transplant patient.

There was only 1 case of HSTCL, characterised by hepatosplenomegaly and cytopenia, which was not associated with EBV, as was the other post-transplant patient included in the study, who presented with SPTCL.

\section{Discussion}

Although EBV-related lymphoproliferative diseases consist mostly of B-cell neoplasms, some $\mathrm{T}$ - and NK-cell lymphoproliferative diseases, especially those with a more aggressive clinical behaviour, have been etiologically linked to chronic, active EBV infection [26]. Since most T- and NK-cell neoplasms exhibiting EBER-positive staining have a cytotoxic T-cell phenotype, it has been proposed that proliferation of cyto- toxic T-cells in response to EBV-infected B-cells plays a role in the pathogenesis of these tumours [10, 27]. However, the exact mechanisms of EBV infection and transformation of T-cells are unknown at this time.

The distribution of various subtypes of NHL shows wide geographic variations between the Western and Eastern parts of the world [8]. Studies gathering information from different geographic areas, including America, Europe, Asia, and South Africa, have documented that mature T- and NK-cell neoplasms comprise about $12 \%$ to $15 \%$ of all NHLs $[2,3]$. The percentage of T- and NK-cell neoplasms among all NHLs is $7 \%$ to $10 \%$ in Western countries $[2,28], 25 \%$ in Korea [29], 21\% in Osaka [30], a region of Japan not endemic for adult T-cell leukaemia/lymphoma, and $18 \%$ in South Taiwan [31]. According to these studies, PTCL, NOS is the most frequent subtype, followed by ALCL, AITCL, and extranodal NK/T-cell lymphoma, nasal type, which comprise $3.7 \%, 2.4 \%$, $1.2 \%$, and $1.4 \%$, respectively, of all NHLs. In con- 
trast, ETTCL, HSTCL, and adult T-cell leukaemia/ lymphoma each comprise $<1 \%$ of all NHLs. PTCL, NOS comprises $9 \%$ to $10 \%$ of NHL cases in the East and $3 \%$ to $4 \%$ of NHL cases in the West [8]. Similar-

Table III. Distribution of EBER positivity in various series of $\mathrm{NK} / \mathrm{T}$ cell lymphomas

\begin{tabular}{lc}
\hline \multicolumn{1}{c}{ Author, COUNTRY AND REFERENCE } & Distribution \\
\hline Harabuchi, Japan 1996 [35] & $16 / 18(89 \%)$ \\
\hline Nakamura, Japan 1997 [36] & $27 / 32(84 \%)$ \\
\hline Cuadra-Garcia, USA 1999 [37] & $13 / 14(93 \%)$ \\
\hline Quintanilla-Martinez, Peru 1999 [15] & $27 / 28(96 \%)$ \\
\hline Gaal, USA 2000 [38] & $14 / 14(100 \%)$ \\
\hline Ko, Korea 2004 [39] & $39 / 51(76 \%)$ \\
\hline Kim, Korea 2003 [40] & $25 / 35(71 \%)$ \\
\hline Kuo, Taiwan 2004 [41] & $22 / 22(100 \%)$ \\
\hline Ng, Singapore 2004 [42] & $41 / 42(98 \%)$ \\
\hline Miyazato, Japan 2004 [30] & $23 / 34(68 \%)$ \\
\hline Tai, Malaysia 2004 [43] & $19 / 20(95 \%)$ \\
\hline Kitamura, Japan 2005 [44] & $31 / 31(100 \%)$ \\
\hline Oshimi, Japan 2005 [34] & $123 / 126(98 \%)$ \\
\hline
\end{tabular}

ly PTCL, NOS was the most prevalent subtype in our patient population, followed by ALCL. However, the second most prevalent type reported was extranodal $\mathrm{NK} / \mathrm{T}$-cell lymphoma, nasal type in Eastern countries, accounting for $4 \%$ to $8 \%$ of all cases of NHL [5, 8 , $30,31]$. The extranodal NK/T-cell lymphoma, nasal type was scarce in our dataset, and adult T-cell leukaemia/lymphoma was not found, which is more similar to Western case series.

The results of our study, presented in Table II, revealed that extranodal NK/T-cell lymphoma, nasal type, exhibited the most significant association with EBV, followed by PTCL, NOS. Some cases of AITCL, ALCL, and ETTCL showed evidence of EBV-positive non-neoplastic cells, discordant with the morphology of neoplastic cells, but consistent with reactive or activated lymphoid cells and/or immunoblasts. All cases of extranodal NK/T-cell lymphoma, nasal type included in this study presented with predominant infiltration of the nasal cavity and a high-grade EBER staining pattern determined by in situ hybridization. A type II latency expressing the latent EBV proteins LMP1, EBNA1, and EBERs has been reported in this entity [32]. Most large series have been reported from Asia and Central and South America

Table IV. Distribution of EBER positivity in various series of T and NK cell lymphomas and comparison with the present study.

\begin{tabular}{|c|c|c|c|c|c|c|c|c|c|c|}
\hline $\begin{array}{l}\text { HISTOPATHO- } \\
\text { LOGICAL } \\
\text { DIAGNOSIS }\end{array}$ & 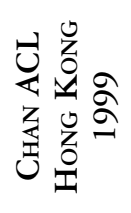 & 预 & 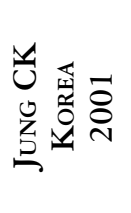 & 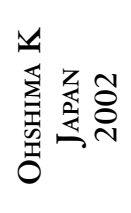 & 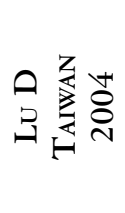 & 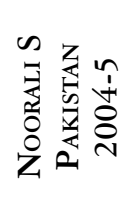 & 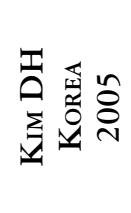 & 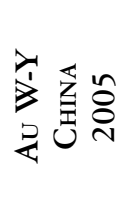 & 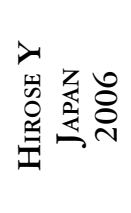 & 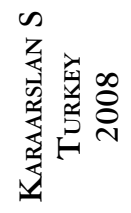 \\
\hline $\begin{array}{l}\text { Extranodal } \\
\text { NK/TCL, } \\
\text { nasal type }\end{array}$ & $\begin{array}{c}24 / 24 \\
(100 \%)\end{array}$ & $\begin{array}{l}47 / 51 \\
(92 \%)\end{array}$ & $\begin{array}{l}9 / 13 \\
(69 \%)\end{array}$ & $\begin{array}{c}18 / 18 \\
(100 \%)\end{array}$ & $\begin{array}{c}14 / 14 \\
(100 \%)\end{array}$ & & $\begin{array}{c}6 / 6 \\
(100 \%)\end{array}$ & $\begin{array}{c}56 / 56 \\
(100 \%)\end{array}$ & $\begin{array}{c}11 / 11 \\
(100 \%)\end{array}$ & $\begin{array}{c}4 / 4 \\
(100 \%)\end{array}$ \\
\hline ETTCL & $\begin{array}{c}3 / 6 \\
(50 \%)\end{array}$ & & & $\begin{array}{c}5 / 13 \\
(38 \%)\end{array}$ & $\begin{array}{c}1 / 2 \\
(50 \%)\end{array}$ & & & $\begin{array}{c}0 / 3 \\
(0 \%)\end{array}$ & & $\begin{array}{c}0 / 3 \\
(0 \%)\end{array}$ \\
\hline HSTCL & & & & $\begin{array}{c}4 / 5 \\
(80 \%)\end{array}$ & & & & $\begin{array}{c}0 / 1 \\
(0 \%)\end{array}$ & & $\begin{array}{c}0 / 1 \\
(0 \%)\end{array}$ \\
\hline SPTCL & & & & & $\begin{array}{c}0 / 1 \\
(0 \%)\end{array}$ & & & $\begin{array}{c}0 / 1 \\
(0 \%)\end{array}$ & & $\begin{array}{c}0 / 1 \\
(0 \%)\end{array}$ \\
\hline PTCL, NOS & $\begin{array}{l}11 / 27 \\
(41 \%)\end{array}$ & $\begin{array}{l}26 / 66 \\
(39 \%)\end{array}$ & $\begin{array}{c}5 / 17 \\
(29 \%)\end{array}$ & & $\begin{array}{c}4 / 22 \\
(18 \%)\end{array}$ & & $\begin{array}{c}5 / 11 \\
(45 \%)\end{array}$ & $\begin{array}{l}16 / 24 \\
(68 \%)\end{array}$ & $\begin{array}{l}18 / 37 \\
(49 \%)\end{array}$ & $\begin{array}{c}10 / 32 \\
(31.3 \%)\end{array}$ \\
\hline ALCL & $\begin{array}{c}0 / 6 \\
(0 \%)\end{array}$ & $\begin{array}{c}3 / 13 \\
(23 \%)\end{array}$ & $\begin{array}{c}0 / 2 \\
(0 \%)\end{array}$ & $\begin{array}{c}0 / 6 \\
(0 \%)\end{array}$ & $\begin{array}{l}1 / 11 \\
(9 \%)\end{array}$ & $\begin{array}{c}2 / 12 \\
(16 \%)\end{array}$ & $\begin{array}{l}0 / 13 \\
(0 \%)\end{array}$ & $\begin{array}{l}0 / 25 \\
(0 \%)\end{array}$ & & $\begin{array}{l}0 / 13 \\
(0 \%)\end{array}$ \\
\hline AITCL & $\begin{array}{c}6 / 7 \\
(86 \%)\end{array}$ & $\begin{array}{c}3 / 4 \\
(75 \%)\end{array}$ & $\begin{array}{c}1 / 1 \\
(100 \%)\end{array}$ & & $\begin{array}{c}6 / 9 \\
(67 \%)\end{array}$ & $\begin{array}{c}8 / 9 \\
(89 \%)\end{array}$ & & $\begin{array}{l}16 / 19 \\
(84 \%)\end{array}$ & $\begin{array}{l}14 / 20 \\
(70 \%)\end{array}$ & $\begin{array}{c}0 / 8 \\
(0 \%)\end{array}$ \\
\hline TOTAL & $\begin{array}{l}44 / 70 \\
(63 \%)\end{array}$ & $\begin{array}{l}79 / 137 \\
(58 \%)\end{array}$ & $\begin{array}{l}15 / 33 \\
(45 \%)\end{array}$ & $\begin{array}{l}27 / 42 \\
(64 \%)\end{array}$ & $\begin{array}{l}26 / 59 \\
(44 \%)\end{array}$ & $\begin{array}{l}10 / 21 \\
(48 \%)\end{array}$ & $\begin{array}{c}5 / 24 \\
(21 \%)\end{array}$ & $\begin{array}{c}88 / 129 \\
(68 \%)\end{array}$ & $\begin{array}{l}43 / 68 \\
(63 \%)\end{array}$ & $\begin{array}{c}14 / 62 \\
(22.6 \%)\end{array}$ \\
\hline
\end{tabular}

PTCL, NOS - peripheral T-cell lymphoma, not otherwise specified; ALCL - anaplastic large cell lymphoma; AITCL - angioimmunoblastic T-cell lymphoma;

ETTCL - enteropatby type T-cell lymphoma; HSTCL - bepatosplenic T-cell lymphoma; SPTCL - subcutaneous panniculitis-like T-cell lymphoma 
[33], and Table III presents a summary of those studies, which used Southern blotting or in situ hybridization techniques to detect viral genomes in extranodal NK/T-cell lymphomas. The incidence of EBV latency has been reported to be $68-100 \%$, including a few reports with a small number of cases from the East. The largest series of extranodal NK-cell lymphoma published to date is by Oshimi et al., who reported 98\% EBER positivity [34].

Miyazato et al. [30] identified EBER-positive staining by in situ hybridization in $83 \%, 36 \%$, and $25 \%$ of nasal, non-nasal, and nodal NK/T-cell lymphomas, respectively. The largest series by Oshimi et al. [34] found EBER-positive cells in 100\% of nasal and $88 \%$ of extranasal cases. In a similar study from Korea [35], 82\% of nasal and $54 \%$ of extranasal NK/T-cell lymphomas and 50\% of PTCL were found to be EBV positive.

In other studies using in situ hybridization for the detection of EBER-positive staining, extranodal NK/ T-cell lymphoma, nasal type has been found to exhibit a significantly higher correlation with EBV-positive cells. A comparison of previous studies with the current work is shown in Table IV.

A few studies have reported an association between EBV and ETTCL by PCR and in situ hybridization. EBER positivity was reported to be $38 \%$ in a Japanese series with 13 patients [36] and 30\% in two different series from Hong Kong comprising a total of 9 patients $[7,9]$. Of the 3 ETTCL cases in the present study, 1 post-transplant patient exhibited EBER-positive staining that was limited to isolated cells resembling reactive or activated lymphocytes and some with immunoblast morphology.

A few studies have reported an aetiological role of EBV using Southern blot and in situ hybridization in patients with HSTCL $[23,37]$. The largest series was a study from France that reported 2 EBER-positive cases of a total of 20 [38]. These 2 cases with pleomorphic cytological features were both of the $\beta F 1$-negative, $\gamma \mathrm{TCR}$-positive $\gamma \delta \mathrm{T}$-cell phenotype. The series of Ohshima et al. [36] from Japan consisted of 4 EBER-positive cases out of a total of 5 with a $\gamma \delta \mathrm{T}$-cell phenotype. The only case in the present study was EBER negative.

SPTCL, a very rare entity, was found to be unrelated to EBV in 2 patients from two different series [5, 7], and 1 patient in the present study (Table IV).

AITCL, a systemic lymphoproliferative disease involving the lymph nodes, spleen, and bone marrow, is especially problematic for inexperienced pathologists, because it is characterised by a polymorphous infiltrate of a neoplastic T-cell population and accompanying reactive $\mathrm{B}$-cells. This challenging disease is diagnosed more frequently after the observation of aberrant CD10 expression on neoplastic T-cells [39]. Some EBV-positive cells were detected in $67-100 \%$ of the cases in previous studies and $62.5 \%$ of our cases $[5,7,9,40,41]$; however, the reaction with EBER was restricted to the reactive B-cell population, rather than neoplastic T-cells. While the latency pattern is unknown, LMP1 and EBERs reflect latency pattern II in these cases.

EBER-positive staining was found in $31.3 \%$ of cases in the heterogeneous PTCL, NOS group, while this group has been reported to exhibit $18-68 \%$ positivity in other studies $[5,7,9,41,42]$.

ALCL has been reported as positive for EBER in situ hybridization in $0 \%$ to $23 \%$ of cases in several studies $[5,7,9,36,40,42]$. However, none of the 13 cases of ALCL were positive in the present study, although 2 cases presented EBER expression that was limited to rare non-neoplastic lymphoid cells.

\section{Conclusions}

The present study of T- and NK-cell lymphomas, which includes the rare and aggressive subtypes of NHL, has demonstrated that PTCL, NOS is the most prevalent type in our geographic area. In parallel with this finding, most of our EBER-positive cases were PTCL, NOS. Extranodal NK/T-cell lymphoma was limited to only 4 cases in this study; however, EBER-positive staining was increased to a statistically significant level and exhibited a more robust staining pattern in this lymphoma subtype $(\mathrm{p}=0.019)$. We have concluded that in situ hybridization is a sensitive method for the identification of EBV in lymphomas and that EBV infection plays an important role in the pathogenesis of nodal or extranodal $\mathrm{T}$ - and NK-cell lymphomas in our area, which is consistent with the findings in Western countries.

The authors declare no conflict of interest.

The authors thank Mrs. H. Uluer for her help in assessing the statistical analysis.

\section{References}

1. Swerdlow SH; International Agency for Research on Cancer. World Health Organization Classification of Tumours of Haematopoietic and Lymphoid Tissues. IARC Press, Lyon 2008.

2. Anon. A clinical evaluation of the International Lymphoma Study Group classification of non-Hodgkin's lymphoma. The Non-Hodgkin's Lymphoma Classification Project. Blood 1997; 89: 3909-3918.

3. Harris NL, Jaffe ES, Stein H, et al. Lymphoma classification proposal: clarification. Blood 1995; 85: 857-860.

4. Aozasa K, Takakuwa T, Hongyo T, et al. NK/T-cell lymphoma: epidemiology and pathogenesis. Int J Hematol 2008; 87: 110-117.

5. Lu D, Lin CN, Chuang SS, et al. T-cell and NK/T-cell lymphomas in southern Taiwan: a study of 72 cases in a single institute. Leuk Lymphoma 2004; 45: 923-928.

6. Kadin ME, Berard CW, Nanba K, et al. Lymphoproliferative diseases in Japan and Western countries: Proceedings of the 
United States-Japan Seminar, September 6 and 7, 1982, in Seattle, Washington. Hum Pathol 1983; 14: 745-772.

7. Au WY, Ma SY, Chim CS, et al. Clinicopathologic features and treatment outcome of mature T-cell and natural killer-cell lymphomas diagnosed according to the World Health Organization classification scheme: a single center experience of 10 years. Ann Oncol 2005; 16: 206-214.

8. Anderson JR, Armitage JO, Weisenburger DD. Epidemiology of the non-Hodgkin's lymphomas: distributions of the major subtypes differ by geographic locations. Non-Hodgkin's Lymphoma Classification Project. Ann Oncol 1998; 9: 717-720.

9. Chan AC, Ho JW, Chiang AK, et al. Phenotypic and cytotoxic characteristics of peripheral T-cell and NK-cell lymphomas in relation to Epstein-Barr virus association. Histopathology 1999; 34: 16-24.

10. Yang L, Aozasa K, Oshimi K, et al. Epstein-Barr virus (EBV)-encoded RNA promotes growth of EBV-infected T cells through interleukin-9 induction. Cancer Res 2004; 64: 5332-5337.

11. Pongpruttipan T, Kummalue T, Bedavanija A, et al. Aberrant antigenic expression in extranodal NK/T-cell lymphoma: a multi-parameter study from Thailand. Diagn Pathol 2011; 6: 79 .

12. Kimura H, Ito Y, Kawabe S, et al. EBV-associated T/NKcell lymphoproliferative diseases in nonimmunocompromised hosts: prospective analysis of 108 cases. Blood 2012; 119: 673686.

13. Mao Y, Zhang DW, Zhu H, et al. LMP1 and LMP2A are potential prognostic markers of extranodal NK/T-cell lymphoma, nasal type (ENKTL). Diagn Pathol 2012; 7: 178.

14. Kanemitsu N, Isobe Y, Masuda A, et al. Expression of Epstein-Barr virus-encoded proteins in extranodal NK/T-cell lymphoma, nasal type (ENKL): differences in biologic and clinical behaviors of LMP1-positive and -negative ENKL. Clin Cancer Res 2012; 18: 2164-2172.

15. Quintanilla-Martinez L, Franklin JL, Guerrero I, et al. Histological and immunophenotypic profile of nasal NK/T cell lymphomas from Peru: high prevalence of $\mathrm{p} 53$ overexpression. Hum Pathol 1999; 30: 849-855.

16. Oshimi K. NK cell lymphoma. Int J Hematol 2002; 76 Suppl 2: 118-121.

17. Tse E, Liang RH. Natural killer cell neoplasms. Clin Lymphoma 2004; 5: 197-201.

18. Tan BT, Warnke RA, Arber DA. The frequency of B- and T-cell gene rearrangements and epstein-barr virus in T-cell lymphomas: a comparisonbetween angioimmunoblastic T-cell lymphoma and peripheral T-cell lymphoma, unspecified with and withoutassociated B-cell proliferations. J Mol Diagn 2006; 8: 466-475.

19. Dupuis J, Emile JF, Mounier N, et al.; Groupe d'Etude des Lymphomes de l'Adulte (GELA). Prognostic significance of Epstein-Barr virus in nodal peripheral T-cell lymphoma, unspecified: A Groupe d'Etude des Lymphomes de l'Adulte (GELA) study. Blood 2006; 108: 4163-4169.

20. Knecht H, Sahli R, Shaw P, et al. Detection of Epstein-Barr virus DNA by polymerase chain reaction in lymph node biopsies from patients withangioimmunoblastic lymphadenopathy. $\mathrm{Br}$ J Haematol 1990; 75: 610-614.

21. De Bruin PC, Jiwa NM, Oudejans JJ, et al. Epstein-Barr virus in primary gastrointestinal $\mathrm{T}$ cell lymphomas. Association with gluten-sensitive enteropathy,pathological features, and immunophenotype. Am J Pathol 1995; 146: 861-867.

22. Quintanilla-Martinez L, Lome-Maldonado C, Ott G, et al. Primary intestinal non-Hodgkin's lymphoma and Epstein-Barr virus: high frequency of EBV-infection in T-cell lymphomas of Mexican origin. Leuk Lymphoma 1998; 30: 111-121.

23. Ohshima K, Haraoka S, Harada N, et al. Hepatosplenic gammadelta T-cell lymphoma: relation to Epstein-Barr virus and activated cytotoxic molecules. Histopathology 2000; 36: 127135.

24. Young LS, Rickinson AB. Epstein-Barr virus: 40 years on. Nat Rev Cancer 2004; 4: 757-768.

25. Chiang AK, Tao Q, Srivastava G, et al. Nasal NK- and T-cell lymphomas share the same type of Epstein-Barr virus latency as nasopharyngeal carcinoma and Hodgkin' sdisease. Int J Cancer 1996; 68: 285-290.

26. Rezk SA, Weiss LM. Epstein-Barr virus-associated lymphoproliferative disorders. Human Pathology 2007; 38: 1293-1304.

27. Young LS, Murray PG. Epstein-Barr virus and oncogenesis: from latent genes to tumors. Oncogene 2003; 22: 5108-5121.

28. Ascani S, Zinzani PL, Gherlinzoni F, et al. Peripheral T-cell lymphomas. Clinico-pathologic study of 168 cases diagnosed according to the R.E.A.L. Classification. Ann Oncol 1997; 8: 583-592.

29. Ko YH, Kim CW, Park CS, et al. REAL classification of malignant lymphomas in the Republic of Korea: incidence of recently recognized entities and changes in clinicopathologic features. Hematolymphoreticular Study Group of the Korean Society of Pathologists. Revised European-American lymphoma. Cancer 1998; 83: 806-812.

30. Miyazato H, Nakatsuka S, Dong Z, et al. NK-cell related neoplasms in Osaka, Japan. Am J Hematol 2004; 76: 230-235.

31. Chuang SS, Lin CN, Li CY. Malignant lymphoma in southern Taiwan according to the revised European-American classification of lymphoid neoplasms. Cancer 2000; 89: 1586-1592.

32. Xu ZG, Iwatsuki K, Oyama N, et al. The latency pattern of Epstein-Barr virus infection and viral IL-10 expression in cutaneous natural killer/T-cell lymphomas. Br J Cancer 2001; 84: 920-5.

33. Chan JK. Peripheral T-cell and NK-cell neoplasms: an integrated approach to diagnosis. Mod Pathol 1999; 12: 177-199.

34. Oshimi K, Kawa K, Nakamura S, et al.; NK-cell Tumor Study Group. NK-cell neoplasms in Japan. Hematology 2005; 10: 237-245.

35. Kim JE, Kim YA, Jeon YK, et al. Comparative analysis of NK/T-cell lymphoma and peripheral T-cell lymphoma in Korea: Clinicopathologicalcorrelations and analysis of EBV strain type and 30-bp deletion variant LMP1. Pathol Int 2003; 53: 735-743.

36. Ohshima K, Liu Q, Koga T, et al. Classification of cell lineage and anatomical site, and prognosis of extranodal T-cell lymphoma - natural killer cell, cytotoxic T lymphocyte, and nonNK/CTL types. Virchows Arch 2002; 440: 425-435.

37. Taguchi A, Miyazaki M, Sakuragi S, et al. Gamma/delta T cell lymphoma. Intern Med 2004; 43: 120-125.

38. Belhadj K, Reyes F, Farcet JP, et al. Hepatosplenic gammadelta T-cell lymphoma is a rare clinicopathologic entity with poor outcome: report on aseries of 21 patients. Blood 2003; 102: 4261-4269.

39. Attygalle AD, Diss TC, Munson P, et al. CD10 expression in extranodal dissemination of angioimmunoblastic T-cell lymphoma. Am J Surg Pathol 2004; 28: 54-61.

40. Noorali S, Pervez S, Yaqoob N, et al. Prevalence and characterization of anaplastic large cell lymphoma and its association with Epstein-Barr virus inPakistani patients. Pathol Res Pract 2004; 200: 669-679.

41. Hirose Y, Masaki Y, Sawaki T, et al. Association of Epstein-Barr virus with human immunodeficiency virus-negative peripheral T-cell lymphomas inJapan. Eur J Haematol 2006; 76: 109-118.

42. Kim D, Ko Y, Suh Y, et al. Characteristics of Epstein-Barr virus associated childhood non-Hodgkin's lymphoma in the Republic of Korea. Virchows Arch 2005; 447: 593-596.

43. Tai YC, Kim LH, Peh SC. High frequency of EBV association and 30-bp deletion in the LMP-1 gene in CD56 lymphomas of the upperaerodigestive tract. Pathol Int 2004; 54: 158-166. 
44. Kitamura A, Yamashita Y, Hasegawa Y, et al. Primary lymphoma arising in the nasal cavity among Japanese. Histopathology 2005; 47: 523-532.

\section{Address for correspondence}

\section{Serap Karaarslan}

Sifa University Faculty of Medicine

Department of Pathology

Sanayi Caddesi No:7

Bornova, Izmir 35100 Turkıye

tel. $+90(232) 3434445$

fax +90 (232) 3435656

e-mail: serapkaraarslan@gmail.com 